\title{
Current Perspectives Regarding The Effects of Muscular Exercise on Neurological Disorders: A Literature Review
}

\author{
MOHAMED M. KHALIFA, M.D.*,** \\ The Department of Human Physiology, College of Medicine, King Saud University, Kingdom of Saudi Arabia* and \\ Faculty of Medicine, Cairo University, Egypt**
}

\begin{abstract}
Regular physical exercise is a well-known mechanism for preventing and treating several health conditions, from the general improvement of the overall health condition and the prevention of obesity and increasing the arterial collateralization and blood flow to the upregulation of antiinflammatory and antioxidant signaling cascades. The beneficial effects of regular physical exercise are far-reaching and diverse.

Chronic neurological disorders are considered a significant public health concern. Given the fact that the available treatment modalities in most neurological conditions are not fully curative and aiming primarily at improving the quality of life and the ability to cope, with a wide side effect profile of the available medications to the high cost of other available methods as electric stimulation devices, this highlight the importance of investigating the beneficial roles of regular physical exercise, both as a preventive and a curative tool, indifferent chronic neurological diseases.
\end{abstract}

This short review of the literature highlights the recent research finding and mechanisms of the beneficial effects of exercise in different chronic neurological diseases.

Key Words: Current perspectives regarding - Muscular exercise - Neurological disorders.

\section{Introduction}

NEUROLOGICAL disorders represent a significant public health challenge due to high prevalence and resistance to complete cure by different treatment modalities, which mandates further research on the prevention and treatment of neurological disorders [1].

From the drugs with detailed side effect profiles to the state-of-the-art electric stimulation devices, the treatment of most neurological disorders is still, unfortunately, inadequate and doesn't provide an adequate cure, aiming at most instances to

Correspondence to: Dr. Mohamed M. Khalifa,

The Department of Human Physiology, College of Medicine, King Saud University, Kingdom of Saudi Arabia and Faculty of Medicine, Cairo University, Egypt improve the patient coping and quality of life rather than giving a full remedial solution [2] .

Hence, dietary, metabolic, and lifestyle changes recently emerged as necessary and useful preventive measures against most neurological disorders [2]

Regular physical exercise is well known to promote health and improve the functions of various body systems. And for the primary prevention of a wide variety of diseases. Most notably, the cardiovascular and musculoskeletal systems [3].

In recent years there has been widespread interest in the link between exercise and brain health. In neurological patient populations, exercise is often prescribed to improve quality of life, increase aerobic capacity, and prevent secondary diseases [4].

\section{Mechanisms of exercise-induced neurological amelioration: \\ Exercise improves synaptic transmission: \\ Different synaptic transmission circuits within the central nervous system are affected by various neurological disorders or even by the normal de- generative and aging processes. Hence the impor- tance of investigating the effects of several thera- peutic and preventive modalities on the process of synaptic transmission [5].}

Recent research results, whether on human or animal models, confirmed the beneficial effects of regular exercise on synaptic transmission in different brain areas. This is consistent with Dahlin et al., 2019, who found that regular physical exercise significantly impacted hippocampal CA1 and dentate gyrus synaptic transmission and long-term potentiation in adolescent and adult experimental rats [6] 
It also concordance with Lin et al., who proved that increased physical activity improved cognitive deficits by increasing various neurotransmitters in the hippocampal region [7].

Several other researchers recently proved an exercise-mediated increase in the level of different neurotransmitters in various brain regions [8,9].

Not only on the higher cortical levels but exercise also improves spinal cord level neurotransmission. And mediates faster recovery following spinal cord injuries [10].

Exercise increases the levels of neurotrophic factors:

Neurotrophic factors are several families of closely related molecules that support the central nervous system's structure and functions. Their functions are diverse and range from apoptosis regulation, maintenance of the neuronal networks, control of normal neurological homeostasis, regulation of neuronal signaling mechanisms, and various other functions [11].

Exercise increases brain neurotrophic factors, which may be important as a modulatory effect in various pathological conditions $[\mathbf{1 2 , 1 3 ]}$

\section{Exercise modulates the neuroinflammatory response:}

Inflammatory response mediates a vast majority of deleterious effects affecting several body systems in various disease conditions. And the nervous system is not an exception [14].

Exaggerated, abnormal, misdirected inflammatory responses are recently implicated as a proposed mechanism for the pathogenesis of multiple abnormalities affecting the nervous system; nevertheless, the fully explained mechanisms are not entirely discovered [14].

Strong activation of the inflammatory cascades in the brain, including the activation of Toll-like receptor (TLR) and the nuclear factor Kappa B cascades, is associated with accelerated rates of neurodegeneration, cytokine overexpression, or dysregulation, glial cell abnormalities, neuronal apoptosis, and eventually multiple structural and functional abnormalities [15].

Physical exercise is well known to induce strong anti-inflammatory effects, with substantial health effects in preventing or treating various disease conditions. Conditions caused by the lack of exercise, notably obesity and type two diabetes mellitus, are recently described as chronic low-grade inflammatory conditions [16]

These effects extend to affect multiple central nervous system areas, including the glial cells in the brain. However, whether these effects are caused by direct modulation of inflammatory cascades within the central nervous system or by a generalized anti-inflammatory impact still needs further investigation [17].

\section{Exercise enhances neuronal repair mechanisms:}

Oxidative or inflammatory stresses are associated with several forms of neuronal injury. Multiple proteins and cytokines are involved in the neuronal repair mechanisms responsible for minimizing oxidative or inflammatory-induced neuronal loss. Regular physical exercise is associated with increased expression of Arginase-1 (Arg 1), chitinaselike 3 (Ym1) and the mannose receptor Mrc-1, and insulin-like growth factor 1 (IGF-1), which are proteins associated with the process of neuronal repair [18]

\section{Exercise upregulates antioxidant mechanisms:}

The overproduction of reactive oxygen species (ROS) can alter the metabolic pathways, impair enzymatic and signaling mechanisms and harm cellular structures such as lipids, proteins, or DNA. Therefore, adequate antioxidant mechanisms are crucial for homeostasis. Physical exercise has been demonstrated to activate several antioxidant signaling pathways and upregulate several of the key enzymes involved in the antioxidant protector response, the most important of which is the Nrf pathway. This endogenous antioxidant system is considered the master antioxidant cytoprotection regulator [19]

\section{Exercise promotes the health of other body} systems:

By the prevention of obesity and the improvement of metabolic and hormonal wellbeing, the general effects of exercise in improving the physiological conditions of other body systems, especially the cardiopulmonary systems, and the prevention of pathophysiological progression of multiple varieties of metabolic disorders, leading to a remarkable impact on the nervous system, improving its blood flow and increasing the expression of neurotrophic factors [20]

Ameliorative effects of Exercise in different neurological diseases:

Demyelinating disorders:

Despite being less physically active than crossmatched healthy controls, patients with chronic 
demyelinating conditions as multiple sclerosis gain remarkable benefits from regular graded physical Exercise [21].

Even in severe disability or dysmobility, even a mild exercise program, or a graded increase in the lifestyle physical activities, carries remarkable health benefits [21].

\section{Seizures disorders:}

Physical activity is beneficial and safe for people with epilepsy. Literature suggests better control of seizures, psychosocial benefits, and significant improvements on the comorbidities [22]

After a careful clinical evaluation, Exercise should be promoted, considering seizure control in the last year, potential triggering factors, and the type of exercise chosen [22]

\section{Parkinson's disease:}

Exercise is proven to facilitate functional performance, i.e., improving trunk mobility, turning, balance, and gait patterns, and reducing the risk of falls in people with PD [23]

Also, there is some evidence to show that strength training effectively improves people with Parkinson's Disease and has some Passover effects in reducing falls and improving quality of life [24]

Also, regular cycling exercise was found to reduce the tremors and ameliorate the balance and bradykinesia in idiopathic Parkinson's disease cases [25].

\section{Cerebrovascular accidents (stroke):}

The pathogenesis and prognosis of cerebrovascular accidents highlight the importance of regular physical Exercise, not only as a treatment of neurological disorders but also as a preventive measure. Physical Exercise is a well-known factor for the primary and secondary prevention of cerebrovascular accidents [26].

Physical Exercise was also found to have neuroprotective effects as a postconditioning factor in cases of ischemic stroke [27].

\section{Mood disorders:}

A - Major depressive disorder:

Regular Exercise was found to improve the mood status in major depressive disorder in a dosedependent manner [28].

Exercise was also proven to reduce the risk of suicide and secondary complications in clinical depression [29].

\section{B- Bipolar disorder:}

Similar effects in reducing the mood disorder symptoms are reported in the literature compared to the action of drugs and aerobic exercise sessions, demonstrating the potential of Exercise in the control and mood stabilization. The increased cardiorespiratory fitness ( $\mathrm{VO} 2 \mathrm{max}$ ) can be an essential means of protection and reducing the possibility of physical and mental damage in bipolar disorders (BD) [30].

\section{Pain syndromes:}

\section{Headache:}

Regular physical exercise exerts remarkably beneficial effects on the quality of life of individuals living with a headache related to different aetiologies. The exercise training effects on the different headache parameters (i.e., intensity, frequency, and pain duration) occur in an intensity-dependent fashion [31]

\section{Fibromyalgia:}

Exercise improved the ability to do daily activities, decreased pain and tiredness, and attenuated stiffness in fibromyalgia cases [32].

\section{Low back pain:}

An exercise program is recommended as a therapeutic regimen for chronic low back pain and other spinal cord disorders [33]

\section{Alzheimer's disease:}

It has been found that physical activities may improve deterioration in cognitive functions and delay the onset of dementia induced by AD [34]

Combining a regular exercise program with vitamin supplementation, [35] or with pharmacological intervention, [36] is considered a potential, effective and novel line for treating Alzheimer's disease, as evidenced by the improved histopathological picture and biochemical markers of the brains of Alzheimer's rats.

\section{Conclusion:}

Regular physical exercise improves the outcome in different classes of chronic neurological conditions via variable mechanisms.

However, the exact mechanisms of amelioration in certain conditions are still in need of further investigation.

\section{References}

1- FISCHELL R.E., FISCHELL D. R. and UPTON A.R.: U.S. Patent No. 6,016,449. Washington, DC: U.S. Patent and Trademark Office, 2000. 
2- RHO J.M. and STAFSTROM C.E.: The ketogenic diet as a treatment paradigm for diverse neurological disorders. Frontiers in Pharmacology, 3, p. 59, 2012.

3- KAMINSKY L.A., ARENA R. and MYERS J.: November. Reference standards for cardiorespiratory fitness measured with cardiopulmonary exercise testing: Data from the Fitness Registry and the Importance of Exercise National Database. In Mayo Clinic Proceedings, (Vol. 90, No. 11, pp. 1515-1523). Elsevier, 2015.

4- SINGH A.M. and STAINES W.R.: The effects of acute aerobic exercise on the primary motor cortex. Journal of motor behavior, 47 (4): pp. 328-339, 2015.

5- SHEN W., JIN L., ZHU A., LIN Y., PAN G., ZHOU S., CHENG J., ZHANG J., TU F., LIU C. and XIE Q.: Treadmill exercise enhances synaptic plasticity in the ischemic penumbra of MCAO mice by inducing the expression of Camk2a via CYFIP1 upregulation. Life Sciences, 270: p.119033, 2021.

6- DAHLIN E., ANDERSSON M., THORÉN A., HANSE E. and SETH H.: Effects of physical exercise and stress on hippocampal CA1 and dentate gyrus synaptic transmission and long-term potentiation in adolescent and adult Wistar rats. Neuroscience, 408: pp. 22-30, 2019.

7- LIN Y., XU Y., FENG H., YOU L., DONG J., GAO Z., PENG S., DENG Y. and WU P.: Involuntary, forced or voluntary exercise can ameliorate the cognitive deficits by enhancing levels of hippocampal NMDAR1, pAMPAR1 and pCaMKII in a model of vascular dementia. Neurological Research, pp. 1-9, 2021.

8- SCHIRINZI T., CANEVELLI M., SUPPA A., BOLOGNA M. and MARSILI L.: The continuum between neurodegeneration, brain plasticity, and movement: A critical appraisal. Reviews in the Neurosciences, 1(ahead-ofprint), 2020.

9- LI C., LIU T., LI R. and ZHOU C.: Effects of exercise on proactive interference in memory: Potential neuroplasticity and neurochemical mechanisms. Psychopharmacology, 237: pp. 1917-1929, 2020.

10- JO H.J. and PEREZ M.A.: Corticospinal-motor neuronal plasticity promotes exercise-mediated recovery in humans with spinal cord injury. Brain, 143 (5): pp. 1368-1382, 2020.

11-FUKUYAMA Y., KUBO M. and HARADA K.: The search for, and chemistry and mechanism of, neurotrophic natural products. Journal of Natural Medicines, pp. 1-24, 2020.

12- BANITALEBI E., GHAHFARROKHI M.M., NEGARESH R., KAZEMI A., FARAMARZI M., MOTL R.W. and ZIMMER P.: Exercise improves neurotrophins in multiple sclerosis independent of disability status. Multiple Sclerosis and Related Disorders, 43: p. 102143, 2020.

13- NILSSON J., EKBLOM Ö., EKBLOM M., LEBEDEV A., TARASSOVA O., MOBERG M. and LÖVDÉN M.: Acute increases in brain-derived neurotrophic factor in plasma following physical exercise relates to subsequent learning in older adults. Scientific Reports, 10 (1): pp. 1$15,2020$.

14- SOCHOCKA M., DINIZ B.S. and LESZEK J.: Inflammatory Response in the CNS: Friend or Foe? Molecular neurobiology, 54 (10): 8071-8089. https://doi.org/ 10.1007/s12035-016-0297-1, 2017.
15- SOCHOCKA M., DINIZ B.S. and LESZEK, J.: Inflammatory response in the CNS: friend or foe?. Molecular Neurobiology, 54 (10): pp. 8071-8089, 2017.

16- ASGHAR A. and SHEIKH N.: Role of immune cells in obesity-induced low-grade inflammation and insulin resistance. Cellular Immunology, 315: pp. 18-26, 2017.

17- MOTA B.C. and KELLY Á.M.: Exercise alters LPSinduced glial activation in the mouse brain. Neuronal Signaling, 4 (4), 2020.

18- LITTLEFIELD A. and KOHMAN R.A.: Differential response to intrahippocampal interleukin-4/interleukin13 in aged and exercise mice. Neuroscience, 343: pp. 106-114, 2017.

19- VARGAS-MENDOZA N., MORALES-GONZÁLEZ Á., MADRIGAL- SANTILLÁN E.O., MADRIGALBUJAIDAR E., ÁLVAREZ-GONZÁLEZ I., GARCÍAMELO L.F., A NGUIANO-ROBLEDO L., FREGOSOAGUILAR T. and MORALES-GONZALEZ J.A.: Antioxidant and adaptative response mediated by Nrf2 during physical exercise. Antioxidants, 8 (6): p. 196, 2019.

20- SLEIMAN S.F., HENRY J., AL-HADDAD R., EL HAYEK L., ABOU HAIDAR E., STRINGER T., ULJA D., KARUPPAGOUNDER S.S., HOLSON E.B., RATAN R.R. and NINAN I.: Exercise promotes the expression of brain derived neurotrophic factor (BDNF) through the action of the ketone body $\beta$-hydroxybutyrate. Elife, 5: p. e15092, 2016.

21- KALB R., BROWN T.R., COOTE S., COSTELLO K., DALGAS U., GARMON E. and MOTL R.W.: Exercise and lifestyle physical activity recommendations for people with multiple sclerosis throughout the disease course. Multiple Sclerosis Journal, 26 (12): 1459-1469, 2020.

22- CARTAGENA Y., CARDONA-GALLÓN D.C., ISAZA S.P. and LADINO L.D.: Exercise as a therapeutic strategy in epilepsy: A literature review. Revista de Neurologia, 71 (1): 31-37, 2020.

23- KHOBKHUN F., HOLLANDS K., HOLLANDS M. and AJJIMAPORN A.:Effectiveness of exercise-based rehabilitation for the treatment of axial rigidity in people with Parkinson's disease: A Scoping Review. Physical Therapy Reviews, 1-9, 2020.

24- CHAMBERLAIN-CARTER J. and JACKSON J.: Does resistance training reduce falls and improve quality of life in people with Parkinson's disease using strength training exercise programs?. Physical Therapy Reviews, $1-9,2020$.

25- DVIRNAK A.C.: The Effects of Bicycling on Tremor and Bradykinesia in Patients with Idiopathic Parkinson's Disease.

26- GARCÍA-CABO C. and LÓPEZ-CANCIO E.: Exercise and Stroke. In Physical Exercise for Human Health (pp. 195-203). Springer, Singapore, 2020.

27- LI F., GENG X., LEE H., WILLS M. and DING Y.: Neuroprotective Effects of Exercise Postconditioning After Stroke via SIRT1-Mediated Suppression of Endoplasmic Reticulum (ER) Stress. Frontiers in Cellular Neuroscience, 15, 20, 2021.

28- MEYER J.D., KOLTYN K.F., STEGNER A.J., KIM J.S. and COOK D.B.: Influence of exercise intensity for 
improving depressed mood in depression: A dose-response study. Behavior Therapy, 47 (4): 527-537, 2016.

29- WEGNER M., AMATRIAIN-FERNÁNDEZ S., KAULITZKY A., MURILLO-RODRIGUEZ E., MACHADO S. and BUDDE H.: Systematic review of meta-analyses: Exercise effects on depression in children and adolescents. Frontiers in Psychiatry, 11: p. 81, 2020.

30- TERASHI T., OTSUKA S., TAKADA S., NAKANISHI K., UEDA K., SUMIZONO M. and SAKAKIMA H.: Neuroprotective effects of different frequency preconditioning exercise on neuronal apoptosis after focal brain ischemia in rats. Neurological Research, 41 (6): 510-518, 2019.

31- MACHADO-OLIVEIRA L., da SILVA GAUTO Y.O., de SANTANA NETO F.J., da SILVA M.G., GERMANOSOARES A.H. and DINIZ, P.R.B.: Effects of different exercise intensities on headache: A systematic review. American Journal of Physical Medicine \& Rehabilitation, 99 (5): pp. 390-396, 2020.

32- BIDONDE J., BUSCH A.J., SCHACHTER C.L., WEBBER S.C., MUSSELMAN K.E., OVEREND T.J., GÓES S.M., DAL BELLO-HAAS V. and BODEN C.: Mixed exercise training for adults with fibromyalgia. Cochrane Database of Systematic Reviews, (5), 2019.
33- CHOU R., DEYO R., FRIEDLY J., SKELLY A., HASHIMOTO R., WEIMER M., FU R., DANA T., KRAEGEL P., GRIFFIN J. and GRUSING S.: Nonpharmacologic therapies for low back pain: A systematic review for an American College of Physicians Clinical Practice Guideline. Annals of Internal Medicine, 166 (7): pp. 493-505, 2017.

34- EBRAHIMI K., MAJDI A., BAGHAIEE B., HOSSEINI S.H. and SADIGH-ETEGHAD S.: Physical activity and beta-amyloid pathology in Alzheimer's disease: A sound mind in a sound body. EXCLI Journal, 16: p. 959, 2017.

35- MEDHAT E., RASHED L., ABDELGWAD M., ABOULHODA B.E., KHALIFA M.M. and EL-DIN S.S.: Exercise enhances the effectiveness of vitamin $D$ therapy in rats with Alzheimer's disease: Emphasis on oxidative stress and inflammation. Metabolic Brain Disease, 35 (1): pp. 111-120, 2020.

36- SAKR H.I., AMEN M.A., RASHED L.A., KHOWAILED A.A., SAYED H.A., MOTAWEE M.E., SAKR H. and KHALIFA M.M.: Comparing prophylactic effect of exercise and metformin on cognitive brain functions in rats with type 3 diabetes mellitus. Archives of Medical Science, $16(1)$.

\title{
وجهات النظر الحديثة بشأن آثار ممارسة الرياضة الهمئة

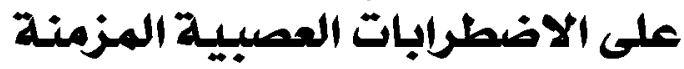

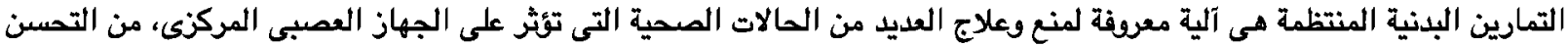

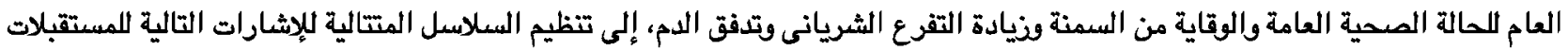

